\title{
Rectal tuberculosis mimicking malignancy: A case report
}

\author{
Art Hiranyakas, Worawit Wanichsuwan, Yik-Hong Ho
}

\begin{abstract}
Introduction: Gastrointestinal tract tuberculosis is uncommon. Anorectal tuberculosis is rare and can mimic malignancy. Case Report: We present a case of circumferential rectal lesion in a 71-year-old male patient who came to the hospital with constipation. Novel imaging investigations could not exclude rectal malignancy. The patient was treated successfully by anti-tuberculosis medications. Conclusion: Rectal tuberculosis should be included in the differential diagnosis of rectal masses. As these lesions occur so infrequently, they are often not suspected.
\end{abstract}

Keywords: Tuberculosis, Rectal cancer, Rectal tuberculosis

$* * * * * * * * *$

Hiranyakas A, Wanichsuwan W, Ho Yik-Hong. Rectal tuberculosis mimicking malignancy: A case report. International Journal of Case Reports and Images 2013;4(5):252-254.

$* * * * * * * * *$

doi:10.5348/ijcri-2013-05-306-CR-3

Art Hiranyakas ${ }^{1}$, Worawit Wanichsuwan ${ }^{2}$, Yik-Hong $\mathrm{Ho}^{3}$

Affiliations: ${ }^{1} \mathrm{MD}$, Bangkok Hospital Group; ${ }^{2} \mathrm{MD}$, Faculty of Medicine Prince of Songkla University; ${ }^{3} \mathrm{MD}$, MBBS(Hon.), James Cook University.

Corresponding Author: Art Hiranyakas, MD, 2/1 Hong-Yok Utis Road, Muang, Phuket, Thailand - 83000; Ph: +66-82570-2130; Fax: +66-76-25-4430; Email: art.hiranyakas@gmail.com

Received: 20 August 2012

Accepted: 10 April 2012

Published: 01 May 2013

\section{INTRODUCTION}

According to the World Health Organization (2007) with the emergence of AIDS/HIV up to one third of the world's population may be infected by Mycobacterium tuberculosis [1]. Gastrointestinal tract tuberculosis may be primary (ingestion of contaminated milk) or secondary (swallowing infected sputum or hematogenous spread) [2]. Even though most tuberculosis is limited to the lungs, extrapulmonary manifestation of tuberculosis have increased from $16 \%$ to 21\% between 1993 and 2005 [2]. Gastrointestinal tuberculosis can present in various forms such as annular stricture or mucosal ulceration with fibrosis which often mimics malignant lesion. The awareness of tuberculosis affecting the rectal region should be borne in mind in the differential diagnosis of a rectal tumor.

\section{CASE REPORT}

A 71-year-old male patient presented with constipation for one month. No rectal bleeding, pain or tenesmus were associated. Patient did not have a history of contact with or any symptoms of pulmonary tuberculosis. Physical examination was unremarkable, but digital rectal examination revealed hard annular growth about five $\mathrm{cm}$ from the anal verge. Colonoscopy showed annular thickening of lower rectum which was covered with a whitish patch (Figure 1). On suspicision of malignancy, multiple biopsies were taken. Endorectal ultrasonography (B-K Medical HAWK 2102; 2050 anorectal radial probe and a $15 \mathrm{MHz}$ transducer) demonstrated a hypoechoic lesion with pseudopodia (Figure 2). Computed tomography confirmed a longitudinal circumferential rectal tumor suggestive of malignancy with multiple pelvic lymphadenopathy (Figure 3).

Endoscopic biopsy showed caseous necrosis with inflammatory cells which was suggestive of tuberculosis (Figure 4). No malignant cells were seen. Chest X-ray showed active pulmonary tuberculosis with positive result for sputum acid fast stain. Anti-HIV ELISA was non-reactive. Serum carcinoembryonic antigen (CEA) 
was $4 \mathrm{ng} / \mathrm{mL}$. Tissue acid fast stain and tissue culture for tuberculosis were negative. Standard six-month anti-tuberculosis medication was prescribed. The patient responded well to the treatment. His constipation improved. His rectal tumor had receded at the six-month endoscopic follow-up.

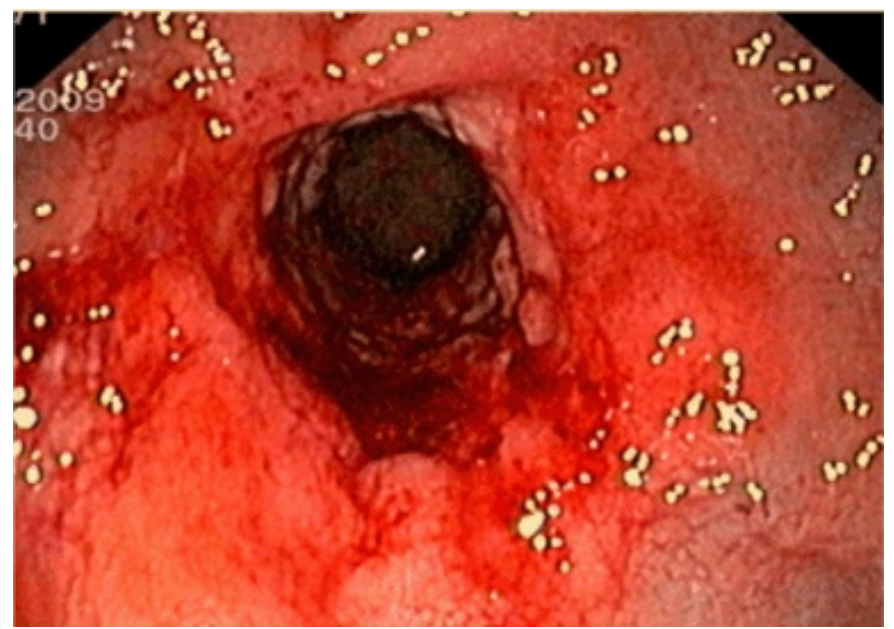

Figure 1: Endoscopic picture showing circumferential (annular) thickening of the rectum.

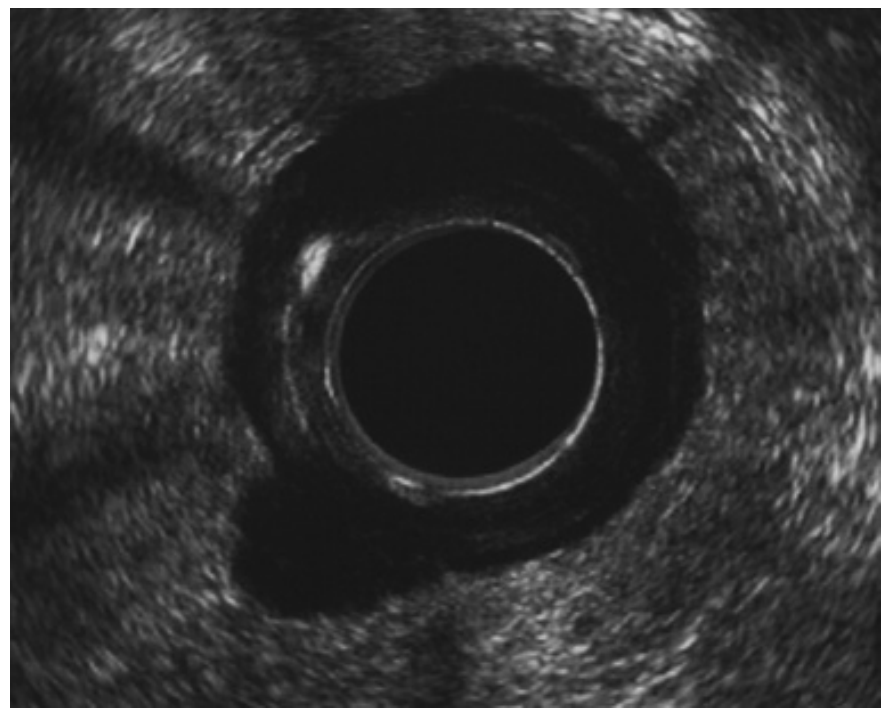

Figure 2: Endorectal ultrasonographic image showing irregular margin of the tumor with pseudopodia.

\section{DISCUSSION}

Extrapulmonary tuberculosis has variety of presentations and is often difficult to diagnosis. Despite the fact that gastrointestinal tuberculosis can involve any part of alimentary tract from the mouth to the anus, anorectal tuberculosis is a rare extrapulmonary form of the disease. Recent literature concerning rectal tuberculosis mimicking malignancy is also limited [3, 4].

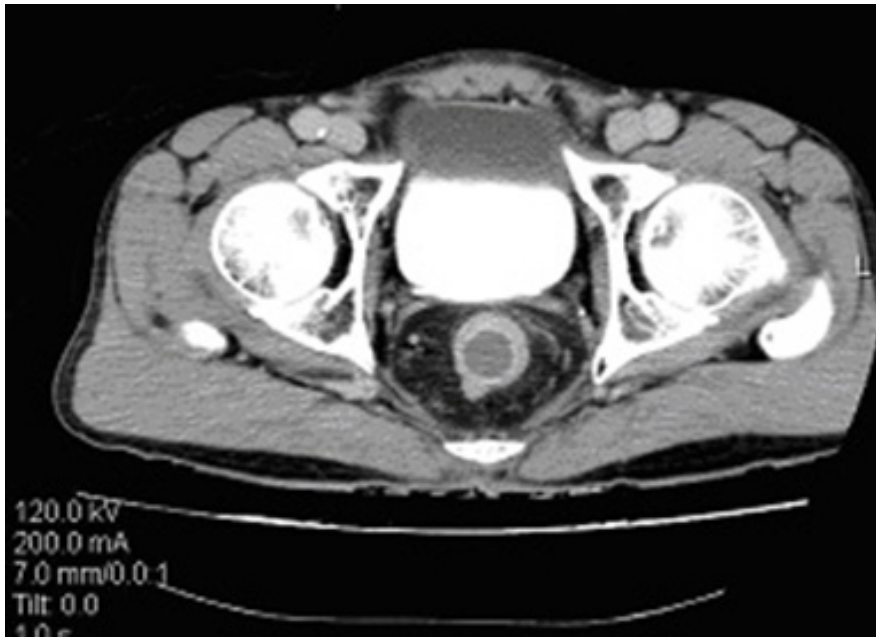

Figure 3: Computed tomography scan showing circumferential (annular) thickening of rectum.

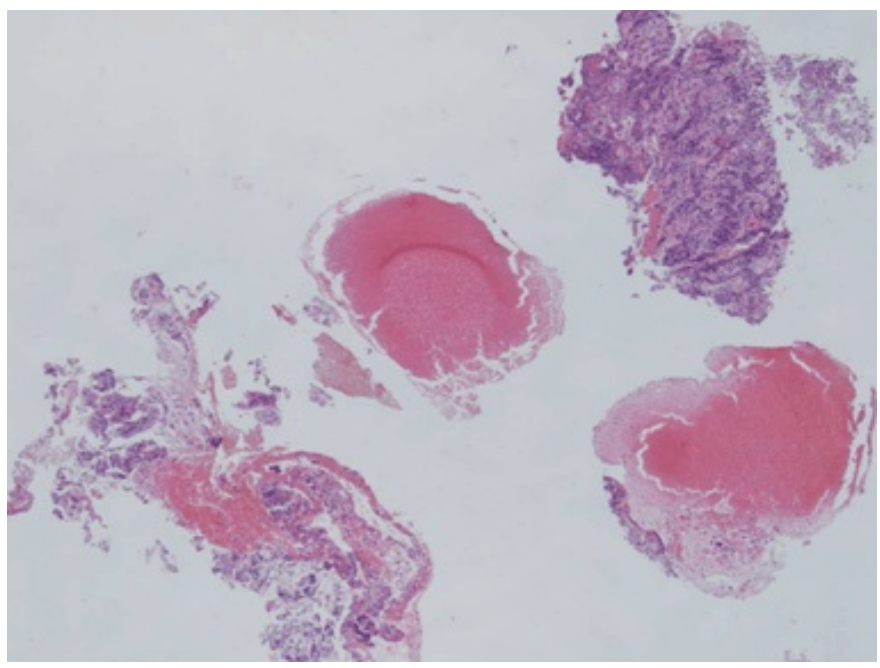

Figure 4: Histopathology from endoscopic biopsy of the rectal tumor showing granulomas and caseous necrosis (H\&E stain, $\mathrm{x} 40$ ).

Usual presentation of rectal tuberculosis is an ulcer, stricture or nodularity in the involved segment. Histological demonstration of chronic granulomatous inflammation with caseation is pathognomonic of tuberculosis. Granulomas are demonstrated in only 27\% biopsies and cultures are positive in $36 \%$ cases [5].

In our case even though provisional diagnosis of rectal carcinoma was made, rectal tuberculosis was suspected after abnormal chest radiography and sputum acid fast stain was positive. Anti-tuberculosis medication was used with satisfactory result in our case.

Recognition of tuberculosis is important because a lack of suspicion may lead to a delay in diagnosis, multiple unnecessary investigations and even unwarranted surgical interventions. 


\section{CONCLUSION}

As the incidence of tuberculosis is increasing as another HIV-related infection, the awareness of tuberculosis affecting the anorectal region should be kept in mind.

$$
* * * * * * * *
$$

\section{Acknowledgements}

Thanks to Dr. Samornmas Kannkurn, the pathologist who reviewed histopathology slides for this case report.

\section{Author Contributions}

Art Hiranyakas - Conception and design, Acquisition of data, Analysis and interpretation of data, Drafting the article, Critical revision of the article, Final approval of the version to be published

Worawit Wanichsuwan - Conception and design, Acquisition of data, Analysis and interpretation of data Yik-Hong Ho - Conception and design, Acquisition of data, Analysis and interpretation of data, Drafting the article, Critical revision of the article

\section{Guarantor}

The corresponding author is the guarantor of submission.

\section{Conflict of Interest}

Authors declare no conflict of interest.

\section{Copyright}

(C) Art Hiranyakas et al. 2013; This article is distributed under the terms of Creative Commons attribution 3.0 License which permits unrestricted use, distribution and reproduction in any means provided the original authors and original publisher are properly credited. (Please see www.ijcasereportsandimages.com/copyright-policy.php for more information.)

\section{REFERENCES}

1. World Health Organization. Treatment of tuberculosis: guidelines for national programmes, 3rd ed. Available at: http://www.who.int/mediacentre/factsheets/fs104/ en/ . Accessed May 5, 2007.

2. Centers for Disease Control and Prevention: Reported tuberculosis in the United States 2005. Atlanta, Ga: U.S. Department of Health and Human Services 2006. Available at: http://www.cdc.gov/tb/surv/surv2005/pdf/TB-

SurvFULLReport.pdf. Accessed November 23, 2007.

3. Sebastian S, Jose T, Kumar KS, Thomas V. Isolated rectal tuberculosis in an AIDS patient masquerading as malignancy. Trop Gastroenterol 2008;29(2):110-1.

4. Kamani L, Ahmed A, Shah M, Hasan S, Jafri W. Rectal tuberculosis: A great mimic. Endoscopy 2007;39 suppl 1:E227-8.

5. Rai RR, Nijhawan S, Bhargava N, et al. Rectal tuberculosis: A case report. Indian $\mathrm{J}$ Tuberculosis 1993;40:35-7.
Access full text article on other devices

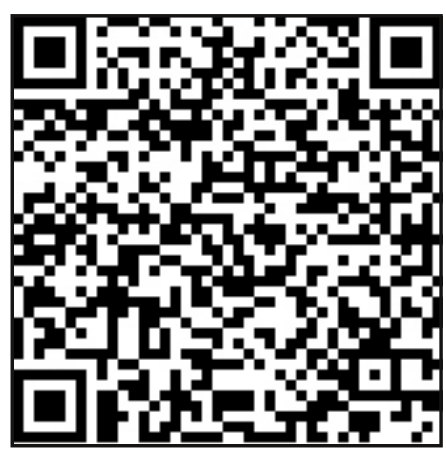

Access PDF of article on other devices

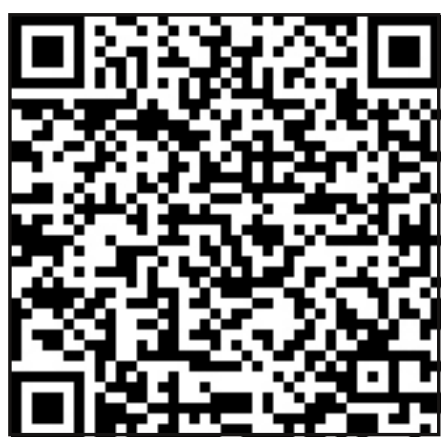

